\title{
Antithrombin Reduces Inflammation and Microcirculatory Perfusion Failure in Closed Soft-Tissue Injury and Endotoxemia
}

\author{
Philip Gierer, $\mathrm{MD}^{1}$; Fabian Laue, $\mathrm{MD}^{1,2}$; Johannes N. Hoffmann, $\mathrm{MD}^{3}$; Robert Rotter, $\mathrm{MD}^{1}$; \\ Thomas Mittlmeier, $\mathrm{MD}^{1}$; Georg Gradl, $\mathrm{MD}^{1}$; Brigitte Vollmar, $\mathrm{MD}^{2}$
}

Background: Closed soft-tissue trauma leads to activation of the coagulation cascade and is often complicated by systemic inflammation and infection. Previous investigations have shown potent anti-inflammatory properties of antithrombin. We herein report on the action of antithrombin on skeletal muscle injury in experimental endotoxemia.

Materials and Methods: By using a pneumatically driven computercontrolled impact device, closed soft-tissue trauma was applied on the left hind limb of pentobarbital-anesthetized rats. Six hours later, endotoxemia was induced by intraperitoneal injection of Escherichia colilipopolysaccharide. An equivalent volume of physiological saline was given in controls. At the same time point, treatment of animals was started by intravenous injection of antithrombin (250 IU/kg body weight) or vehicle solution. Twenty-four hours after trauma, the extensor digitorum longus muscle was microsurgically exposedandanalyzed bymeans ofhigh-resolutionmultifluorescence microscopy.

Results: Traumatic soft-tissue injury with additional endotoxemia was characterized by nutritive perfusion failure (functional capil- lary density: $379 \pm 20 \mathrm{~cm} / \mathrm{cm}^{2}$ ), tissue hypoxia (nicotinamide adenine dinucleotide autofluorescence: $77 \pm 4 \mathrm{aU}$ ), and enhanced leukocyte-endothelial cell interaction $\left(773 \pm 35\right.$ cells $\left./ \mathrm{mm}^{2}\right)$. Therapeutic intervention with antithrombin $6 \mathrm{hrs}$ after trauma restored nutritive perfusion and tissue oxygenation (functional capillary density: $469 \pm 22 \mathrm{~cm} / \mathrm{cm}^{2}$; nicotinamide adenine dinucleotide autofluorescence: $61 \pm 5 \mathrm{aU}[p<0.05])$ and reduced inflammatory leukocyte adherence $\left(237 \pm 20\right.$ cells $\left./ \mathrm{mm}^{2}[p<0.05]\right)$ toward values found in nontraumatized controls (functional capillary density: $573 \pm 13 \mathrm{~cm} / \mathrm{cm}^{2}$; nicotinamide adenine dinucleotide autofluorescence: $56 \pm 2 \mathrm{aU}$; leukocyte adherence: $204 \pm 20$ cells $/ \mathrm{mm}^{2}$ ). Conclusion: Antithrombin ameliorates microcirculatory dysfunction and tissue injury in traumatized animals during endotoxemia. Furthermore, a reduced inflammatory cell response helps to prevent leukocyte-dependent secondary tissue injury. (Crit Care Med 2013; 41:867-873)

Key Words: antithrombin; endotoxemia; lipopolysaccharide; microcirculation; nicotinamide adenine dinucleotide fluorescence; trauma.

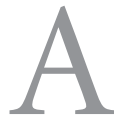
mong the factors influencing the outcome of complex injuries to the extremities, the severity of the associated soft-tissue trauma is still one of the most decisive prognostic determinants. Due to the alarming frequency of high-velocity/high-energy traffic victims, the prevalence of severe softtissue trauma still continues to increase. Extensive trauma leads to activation of the coagulation cascade and is often compli-

\footnotetext{
${ }^{1}$ Department of Trauma \& Reconstructive Surgery, University of Rostock, Rostock, Germany.

${ }^{2}$ Institute for Experimental Surgery, University of Rostock, Rostock, Germany.

${ }^{3}$ Department of Surgery, Klinikum Großhadern, Ludwig-MaximiliansUniversity, Munich, Germany.

The authors have not disclosed any potential conflicts of interest.

For information regarding this article, E-mail: philip.gierer@med.uni-rostock.de

Copyright (C) 2013 by the Society of Critical Care Medicine and Lippincott Williams \& Wilkins
}

DOI: $10.1097 / C C M .0 b 013 e 3182742 \mathrm{~d} 2 \mathrm{c}$ cated by systemic inflammation and infection leading to multiple organ dysfunction syndrome (MODS). Sepsis-induced MODS represents the leading cause of death in postoperative and post-traumatic ICUs (1). Modulation of the coagulatory response following trauma and sepsis allows one to affect key features of the pathogenesis of septic shock $(2,3)$. Antithrombin III, a plasma-derived serine protease inhibitor, controls the activity of thrombin and other proteases of the coagulation cascade $(4,5)$. Furthermore, antithrombin has previously shown a large number of anti-inflammatory actions, independent of its anticoagulatory effects (6-8). It is supposed that antithrombin interacts with endothelial cells, thus inhibiting leukocyteendothelial cell interaction. On the other hand, a direct action of antithrombin on leukocyte activation with inhibition of the release of proinflammatory mediators is discussed (5).

To date, however, it has not been investigated whether administration of antithrombin is indeed of therapeutic benefit for traumatized soft tissue. Thus, the aim of our study 
was to assess the effects of antithrombin on microvascular nutritive perfusion and local inflammatory cell response in skeletal muscle in a model of closed soft-tissue injury and endotoxemia.

\section{MATERIALS AND METHODS}

\section{Animal Model}

The experimental protocol was approved by the local animal rights protection authorities and followed the National Institutes of Health guidelines for the care and use of laboratory animals. A total of 35 male Sprague-Dawley rats (body weight [bw]: 250-300g) were anesthetized with $6 \%$ pentobarbital sodium $(55 \mathrm{mg} / \mathrm{kg}$ bw IP; Narcoren; Merial, Hallbergmoos, Germany). By means of a pneumatically driven and computercontrolled impact device, a standardized soft-tissue trauma was induced in 28 animals on the lateral compartment of the left hind limb, simulating high-velocity trauma of the lower extremity (9). The controlled-impact technique was initially developed as a model of experimental traumatic brain injury in rats, reproducing the pathophysiologic and morphologic responses of severe closed head injury as found in humans (10, 11). The controlled-impact device consists of a compressed nitrogen gas source, an adjustable impactor, a displacement transducer, and a personal computer-assisted interface for data transmission and analysis of time/displacement parameter of the impact. The impact parameters were selected to an impact velocity of $7 \mathrm{~m} / \mathrm{s}$, a deformation depth of $11 \mathrm{~mm}$, and an impact duration of $100 \mathrm{msec}$ with an impactor diameter of $10 \mathrm{~mm}$. The left hind limb was placed in a plastic mold (Technovit; Kulzer, Wertheim, Germany) shaped like the hind limb to guarantee optimal energy transmission to the tissue by avoiding hind limb movement during the impact.

Six hours after trauma induction, animals underwent a second hit by intraperitoneal injection of Escherichia coli lipopolysaccharide $(10 \mathrm{mg} / \mathrm{kg}$ bw IP; serotype 128:B12, Sigma, Taufkirchen, Germany) (trauma/lipopolysaccharide; $n=7$ ) or the equal volume of saline for control (trauma; $n=7$ ). Subsequent to lipopolysaccharide or saline exposure, animals were treated with antithrombin $(250 \mathrm{IU} / \mathrm{kg}$ bw [Atenative, Octapharma, Langenfeld, Germany]; therapy/lipopolysaccharide; $n$ $=7$ and therapy; $n=7)$. Following the identical protocol, nontraumatized animals served as controls ( $\operatorname{sham;} n=7$ ). Twentyfour hours after trauma induction, all animals were anesthetized again and placed on a heating pad for maintenance of body temperature at $37^{\circ} \mathrm{C}$. Following tracheotomy, animals were mechanically ventilated (tidal volume: $1 \mathrm{~mL} / 100 \mathrm{~g}$ bw; 50 breaths/min). Catheters (PE-50; Portex, Hythe, Kent, UK) were placed in the right carotid artery and left jugular vein for continuous monitoring of central hemodynamics (Sirecust; Siemens, Germany).

The left extensor digitorum longus (EDL) muscle was microsurgically prepared to allow direct access for in vivo high-resolution multifluorescence microscopy. The preparation technique was first described by Tyml and Budreau (12) and modified for in vivo microscopy by our group (9). During preparation, tissues were superfused with $37^{\circ} \mathrm{C}$ warm physiological saline solution to prevent drying. After final exposure of the EDL muscle, tissue was covered with a cover glass.

After baseline recordings (inclusion criteria-mean arterial blood pressure: $100-110 \mathrm{~mm} \mathrm{Hg}$, hematocrit: $45 \%-50 \%, \mathrm{pCo}_{2}$ : $35-40 \mathrm{~mm} \mathrm{Hg}$, and pH: 7.35-7.45) and a 20-min stabilization period after completion of surgery, in vivo microscopy of the EDL muscle was performed. At the end of the experiments, animals were killed by exsanguination. Muscle tissue was sampled for subsequent histology and immunohistochemistry.

In Vivo Fluorescence Microscopy. For in vivo analysis of the muscle tissue, the surface of the EDL muscle was sequentially scanned from the distal to the proximal part. To reliably assess the microcirculation in the muscle, microscopic images from ten observation areas in each muscle were recorded (9). After intravenous injection of fluorescein isothiocyanate-labeled dextran ( $15 \mathrm{mg} / \mathrm{kg}$ bw; Sigma, Deisenhofen, Germany) and rhodamine $6 \mathrm{G}(0.15 \mathrm{mg} / \mathrm{kg} \mathrm{bw}$; Sigma), in vivo microscopy was performed using a Nikon microscope (E600-FN, Nikon, Tokyo, Japan) equipped with a $100 \mathrm{~W}$ mercury lamp and filter sets for blue (excitation/emission: $465-495 \mathrm{~nm}$ or $>505 \mathrm{~nm}$ ), green $(510-560 \mathrm{~nm}$ or $>575 \mathrm{~nm})$, and ultraviolet $(340-380 \mathrm{~nm}$ or $>400 \mathrm{~nm}$ ) epi-illumination. By use of water-immersion objectives $(\times 20 / 0.75 \mathrm{~W}$ and $\times 40 / 0.80 \mathrm{~W}$, Nikon), final magnifications of $\times 306$ and $\times 630$ were achieved. Images were recorded by means of a charge-coupled device video camera (FK 6990IQ-S, Pieper, Schwerte, Germany) and transferred to an S-VHS video system for subsequent offline analysis. For analysis of apoptotic cell death, in vivo staining of myocyte nuclei was achieved by intravenous injection of bisbenzimide $(10 \mu \mathrm{mol} /$ kg bw; Hoechst 33342, Sigma).

Microcirculatory Analysis. For quantitative offline analysis, a computer-assisted microcirculation image analysis system was used (CapImage v7.4, Zeintl, Heidelberg, Germany). As previously described $(9,13,14)$, functional capillary density was defined as the total length of red blood cell-perfused capillaries per observation area and given in $\mathrm{cm} / \mathrm{cm}^{2}$. With use of densitometric techniques, macromolecular leakage was assessed in several fields per image and expressed as the ratio of fluorescence intensity selected from the perivascular area to the corresponding intravascular area (plasma gaps in the microvessels between erythrocytes [15]). For assessment of leukocyte-endothelial cell interaction in postcapillary venules, flow behavior of leukocytes was analyzed with respect to free floating, rolling, and adherent leukocytes. Rolling leukocytes were defined as those cells moving along the vessel wall at a velocity less than $40 \%$ of that of leukocytes at the centerline and were expressed as a percentage of the total leukocyte flux. Venular leukocyte adherence was defined as the number of leukocytes not moving or detaching from the endothelial lining of the venular vessel wall during an observation period of $20 \mathrm{~s}$. Assuming cylindrical microvessel geometry, leukocyte adherence was expressed as nonmoving cells per endothelial surface $\left(\mathrm{n} / \mathrm{mm}^{2}\right)$, calculated from the diameter and length of the vessel segment analyzed. In postcapillary venules, centerline red blood cell velocity was determined using the line shift method 
(CapImage, Dr. Zeintl Software, Heidelberg, Germany). To minimize bias in selection of venules with respect to the local leukocyte-endothelial cell interaction, postcapillary venules were chosen during visualization in blue light epi-illumination, which does not allow visualizing leukocyte flow behavior. Thereafter, filter set was changed to green light epi-illumination for assessment of inflammatory leukocyte response. Reduced nicotinamide adenine dinucleotide (NADH) fluorescence of skeletal muscle tissue was densitometrically assessed after $2 \mathrm{~s}$ of ultraviolet epi-illumination by computer-assisted gray level determination (16). To avoid interference of gray levels with microvascular structures, analysis was strictly limited to the intercapillary space. Within ten observation fields of skeletal muscle, apoptotic cell death was assessed by counting the number of bisbenzimide-stained cells that showed apoptosisassociated condensation, fragmentation, and crescent-shaped formation of their nuclear chromatin $(17,18)$.

\section{Laboratory Analysis}

Arterial blood samples were withdrawn for analysis of blood gases (Rapidlab 348, Bayer Vital, Fernwald, Germany) and blood cell count using a Coulter counter (AcTdiff, Coulter, Hamburg, Germany).

Histology and Immunohistochemistry. At the end of each experiment, EDL muscle tissue was fixed in $4 \%$ phosphatebuffered formalin for 2-3 days and then embedded in paraffin. From the paraffin-embedded tissue blocks, $4-\mu \mathrm{m}$ sections were cut and exposed to an apoptosis-specific staining kit (indirect in situ DNA nick-end labeling [terminal deoxynucleotidyl transferase dUTP nick-end labeling, TUNEL] assay, ApopTag; Chemicon
International Inc., Temecula, CA) according to the manufacturer's instructions. Quantitative analysis was performed by counting the number of TUNEL positive tissue-confined cells in 50 consecutive high-power fields (HPF; $\times 400$ magnification). For quantitative assessment of leukocyte tissue infiltration, tissue specimens were stained by the AS-D chloroacetate esterase technique. Leukocytes were identified by positive staining and morphology in 50 HPF in a blinded fashion using a light microscopy ( $\times 40$ objective) and recorded by the number of cells/HPF.

Statistical Analysis. Results were given as mean \pm SEM. After proving the assumption of normality (KolmogorovSmirnov), comparisons between the experimental groups were performed by a univariate analysis of variance, followed by the Bonferroni post hoc multiple comparison procedure (SigmaStat, Jandel, San Rafael, CA). To assess the correlation between different microcirculatory parameters, linear regression analysis was used. Statistical significance was set at $p<0.05$.

\section{RESULTS}

\section{Systemic Hemodynamics}

Animals that underwent local soft-tissue trauma and endotoxemia revealed increased heart rate and pronounced thrombocytopenia when compared with non-lipopolysaccharide-exposed and sham-operated animals. No changes were observed for hemoglobin, leukocyte count, electrolytes, and blood clotting parameters (Table 1).

\section{TABLE 1. Systemic Hemodynamics and Blood Cell Count and Clotting Parameters}

\begin{tabular}{|c|c|c|c|c|c|}
\hline & Sham & Trauma & $\begin{array}{c}\text { Trauma/ } \\
\text { Lipopolysaccharides }\end{array}$ & Therapy & $\begin{array}{c}\text { Therapy/ } \\
\text { Lipopolysaccharides }\end{array}$ \\
\hline \multicolumn{6}{|l|}{ Hemodynamics } \\
\hline $\begin{array}{l}\text { Mean arterial blood } \\
\text { pressure }(\mathrm{mm} \mathrm{Hg})\end{array}$ & $109 \pm 7$ & $111 \pm 10$ & $111 \pm 7$ & $107 \pm 4$ & $99 \pm 7$ \\
\hline Heart rate (beats/min) & $364 \pm 8$ & $377 \pm 17$ & $420 \pm 11^{a}$ & $382 \pm 17$ & $417 \pm 8^{a}$ \\
\hline \multicolumn{6}{|l|}{ Blood parameters } \\
\hline Hemoglobin (mmol/L) & $8.8 \pm 0.3$ & $8.3 \pm 0.2$ & $8.6 \pm 0.2$ & $8.0 \pm 0.3$ & $8.4 \pm 0.1$ \\
\hline Hematocrit (\%) & $43 \pm 4$ & $42 \pm 1$ & $42 \pm 1$ & $41 \pm 4$ & $40 \pm 1$ \\
\hline Thrombocytes (109/L) & $752 \pm 61$ & $776 \pm 70$ & $160 \pm 66^{a-c}$ & $694 \pm 118$ & $157 \pm 53^{a-c}$ \\
\hline Leukocytes (109/L) & $8.5 \pm 0.7$ & $8.3 \pm 0.9$ & $11.1 \pm 2.2$ & $11.4 \pm 1.8$ & $10.3 \pm 1.3$ \\
\hline $\mathrm{Na}^{+}(\mathrm{mmol} / \mathrm{L})$ & $139 \pm 3$ & $139 \pm 1$ & $140 \pm 1$ & $140 \pm 1$ & $139 \pm 1$ \\
\hline $\mathrm{K}^{+}(\mathrm{mmol} / \mathrm{L})$ & $3.9 \pm 0.4$ & $3.9 \pm 0.1$ & $4.0 \pm 0.3$ & $4.1 \pm 0.1$ & $3.8 \pm 1.6$ \\
\hline Thromboplastin time (\%) & $149 \pm 1$ & $141 \pm 5$ & $135 \pm 6$ & $135 \pm 1$ & $135 \pm 0$ \\
\hline Partial thromboplastin time (s) & $26.0 \pm 3.4$ & $22.3 \pm 0.9$ & $30.2 \pm 3.7$ & $29.4 \pm 1.3$ & $29.4 \pm 1.3$ \\
\hline
\end{tabular}

Values are given as mean \pm SEM. Blood samples were withdrawn at $24 \mathrm{~h}$ after soft-tissue trauma.

${ }^{a} p<0.05$ vs. sham.

${ }^{\mathrm{b}} p<0.05$ vs. trauma.

${ }^{\mathrm{c}} p<0.05$ vs. therapy. 


\section{Microvascular Perfusion}

Closed soft-tissue trauma and trauma with subsequent endotoxemia caused a tremendous impairment of functional capillary density with values less than $400 \mathrm{~cm} / \mathrm{cm}^{2}$. Treatment with antithrombin restored nutritive capillary perfusion in endotoxemic animals (therapy/lipopolysaccharide: $469 \pm 22 \mathrm{~cm} /$ $\mathrm{cm}^{2}$ ) and nonendotoxemic animals (therapy: $438 \pm 29 \mathrm{~cm} / \mathrm{cm}^{2}$ ), however, not reaching physiologic baseline values (Fig. 1A). In line with nutritive perfusion failure, significantly increased NADH autofluorescence of skeletal muscle tissue was observed
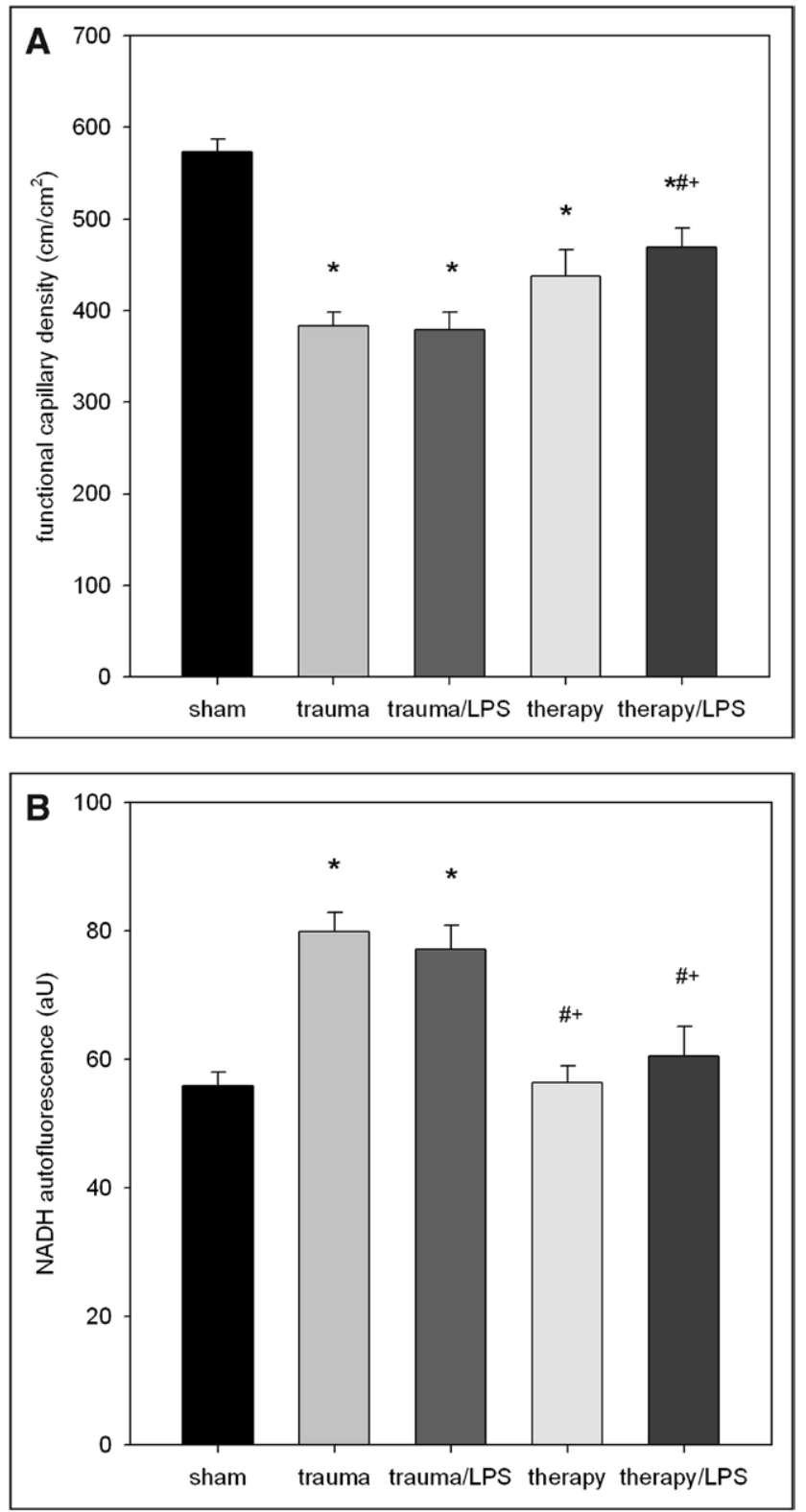

Figure 1. Functional capillary density $(\mathbf{A})$ and nicotinamide adenine dinucleotide $(\mathrm{NADH})$ autofluorescence $(\mathbf{B})$ of skeletal muscle tissue at 24 hrs after soft-tissue trauma and subsequent exposure to lipopolysaccharide (LPS). Animals were treated either with antithrombin (therapy; therapy/LPS) or vehicle solution (trauma; trauma/LPS). Sham-operated animals without trauma and endotoxemia (sham) served as controls. Values are given as mean \pm SEM. ${ }^{*} p<0.05$ vs. sham; $\# p<0.05$ vs. trauma, $+p<0.05$ vs. trauma/LPS. after closed soft-tissue injury (trauma: $80 \pm 2 \mathrm{aU}$ ) and after subsequent endotoxemia (trauma/lipopolysaccharide: $77 \pm 4 \mathrm{aU}$ ), indicating pronounced tissue hypoxia. In contrast, animals treated with antithrombin exhibited significant reduction of tissue NADH (therapy: $57 \pm 3$ aU; therapy/lipopolysaccharide: $61 \pm 5 \mathrm{aU}$ ), further underlining the concomitant improvement of capillary perfusion (Fig. 1B). Regression analysis revealed a significant inverse correlation between functional capillary density and NADH autofluorescence of skeletal muscle tissue with a regression coefficient of $r=-0.51(p<0.05)$. Macromolecular leakage increased upon trauma and endotoxemia. Therapeutic intervention with antithrombin was accompanied by a significantly reduced macromolecular leakage, as found in nontraumatized animals (Fig. 2). Capillary diameters and red blood cell velocity did not significantly differ among the groups, indicating comparable microhemodynamic conditions.

\section{Inflammatory Cell Response}

Soft-tissue trauma alone as well as in combination with endotoxemia provoked a marked inflammatory cell response with leukocytes rolling along and firmly attaching (Table 2) to the venular endothelium. Antithrombin effectively limited the inflammatory response with reduced numbers of leukocytes interacting with the postcapillary venular endothelium after both trauma and trauma with the subsequent endotoxic hit (Table 2). In line with in vivo fluorescence microscopic analysis of leukocyte-endothelial cell interaction, histology of traumatized muscle tissue revealed an inflammatory cell infiltration,

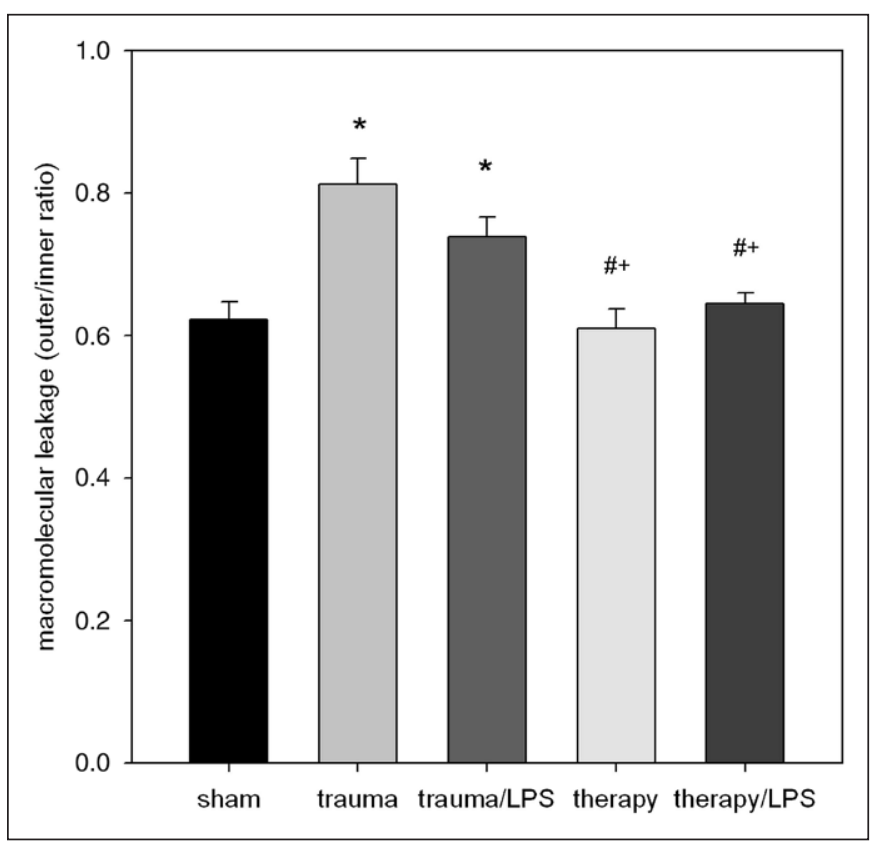

Figure 2 . Macromolecular leakage of fluorescein isothiocyanate dextran (ratio) within skeletal muscle tissue at 24 hrs after soft-tissue trauma and subsequent exposure to lipopolysaccharide (LPS). Animals were treated either with antithrombin (therapy; therapy/LPS) or vehicle solution (trauma; trauma/LPS). Sham-operated animals without trauma and endotoxemia (sham) served as controls. Values are given as mean \pm SEM; ${ }^{*} p<0.05$ vs. sham; $\# p<0.05$ vs. trauma, and $+p<0.05$ vs. trauma/LPS. 
TABLE 2. Leukocyte-Endothelial Cell Interaction

\begin{tabular}{lccccc} 
& Sham & Trauma & $\begin{array}{c}\text { Trauma/Lipopoly } \\
\text { saccharides }\end{array}$ & Therapy & $\begin{array}{c}\text { Therapy/Lipopoly } \\
\text { saccharides }\end{array}$ \\
\hline Leukocyte rolling $(\%)$ & $30 \pm 2$ & $41 \pm 5$ & $48 \pm 3^{\mathrm{a}}$ & $43 \pm 2$ & $48 \pm 3^{\mathrm{a}}$ \\
Leukocyte adherence $\left(\mathrm{n} / \mathrm{mm}^{2}\right)$ & $204 \pm 20$ & $686 \pm 37^{\mathrm{a}}$ & $773 \pm 35^{\mathrm{a}}$ & $176 \pm 38^{\mathrm{b}, \mathrm{c}}$ & $237 \pm 20^{\mathrm{b}, \mathrm{c}}$ \\
\hline
\end{tabular}

Values are given as mean \pm SEM. Blood samples were withdrawn at $24 \mathrm{~h}$ after soft-tissue trauma.

${ }^{\mathrm{a}} p<0.05$ vs. sham.

${ }^{\mathrm{b}} p<0.05$ vs. trauma.

${ }^{c} p<0.05$ vs. trauma/lipopolysaccharides.

which was reduced in antithrombin-treated animals (data not shown).

\section{Tissue Cell Death}

Upon trauma, nontreated animals revealed enhanced numbers of apoptotic muscle cell nuclei, both in vivo and by indirect in situ DNA nick-end labeling (TUNEL) assay. Treatment with antithrombin reduced apoptotic cell death in both methods (Fig. $3 \boldsymbol{A}$ and $\boldsymbol{B})$.

\section{DISCUSSION}

In this study, we could show that antithrombin prevents leukocyte adherence, microvascular perfusion failure, and microvascular leakage in traumatized skeletal muscle tissue under conditions of systemic endotoxemia. With respect to the fact that the severity of soft-tissue trauma is a critical prognostic factor for morbidity and mortality following complex injuries of the extremities (13), the findings allow one to conclude that treatment with antithrombin might reduce secondary tissue damage.

Antithrombin III has been shown to reduce mortality rate and to prevent organ dysfunction in different animal models $(19,20)$. Furthermore, antithrombin was capable in delaying microvascular thrombus formation in a murine model $(21,22)$. Beside its anticoagulatory actions, antithrombin reveals anti-inflammatory activities in a variety of experimental models, which are independent of its direct influence on the coagulatory cascade $(7,23)$. Beneficial effects of antithrombin could also be shown in patients with severe sepsis (24), which, however, have not been confirmed in the multinational KyberSept trial (25). Despite the fact that antithrombin application is currently not recommended as an adjunctive therapy by the surviving sepsis campaign guidelines (26), there is evidence for antithrombin to effectively reduce mortality rate in a subgroup of septic patients not receiving heparin (27). To our knowledge, the benefit of antithrombin application on traumatized skeletal muscle tissue in an experimental set-up comparable to the present one has not been investigated yet.

The animal model used in this study was formerly described by our group and allows the intravital fluorescence microscopy of traumatized skeletal muscle for quantitative analysis of microvascular perfusion and inflammatory cell interaction under endotoxemic conditions $(9,28)$. Soft-tissue trauma alone leads to an increase in leukocyte-endothelial cell interaction and a marked reduction in capillary perfusion. In line with nutritive perfusion failure, high-NADH autofluorescence was observed, indicating local tissue hypoxia (25). In general, interruption of oxidative phosphorylation caused by inadequate oxygen supply is reflected by an increase of NADH levels (29). Thus, in vivo $\mathrm{NADH}$-fluorescence microscopy allows noninvasive investigation of organ metabolism as a result of alterations in oxidative phosphorylation (17). In line with this, we could demonstrate a strong negative regression between NADH autofluorescence and microvascular perfusion within the traumatized skeletal muscle tissue. Microcirculatory disorders were even more pronounced by the additional lipopolysaccharide challenge $6 \mathrm{hrs}$ after trauma induction, representing an endotoxemic second hit, which probably leads to thrombotic occlusion of microvessels secondary to the perfusion failure caused by capillary microdamage by the soft-tissue trauma itself. Treatment with antithrombin was capable in modulating these trauma- and endotoxemia-induced microvascular sequelae.

It is known that the glycocalyx, a layer of glucosaminoglycans on the endothelial surface, is impaired in sepsis, thus enabling interaction of white blood cells and platelets with the endothelial surface $(30,31)$. Massive leukocyte rolling and adherence to the endothelial surface in both endotoxemic animals and animals with isolated soft-tissue trauma could be demonstrated. Furthermore, we observed a significant decrease in platelet counts in endotoxemic animals, indicating a septic consumption coagulopathy caused by increased interaction of platelets with the endothelial surface (30). These consumed thrombocytes cannot be restored by antithrombin but have to be reproduced, which takes longer than the observation time is. Thrombocytopenia was not induced by soft-tissue trauma alone. This issue might be due to the fact that trauma alone leads to a circumscribed endothelial damage with only local increase of cell-cell interaction, in contrast to a systemic impairment of the endothelial surface in sepsis.

Antithrombin was highly effective in preventing leukocyte adherence to the venular endothelium. Antithrombin-treated animals revealed values of leukocyte adherence comparable to those in sham controls. The mechanism of action remains controversial. While some authors credit the effect of antithrombin on leukocyte-endothelial cell interaction with its anticoagulant activity as the primary mechanism of action (32), others assume the mechanism being independent on the coagulatory pathway $(8,30)$. Further studies are needed to fully characterize the 

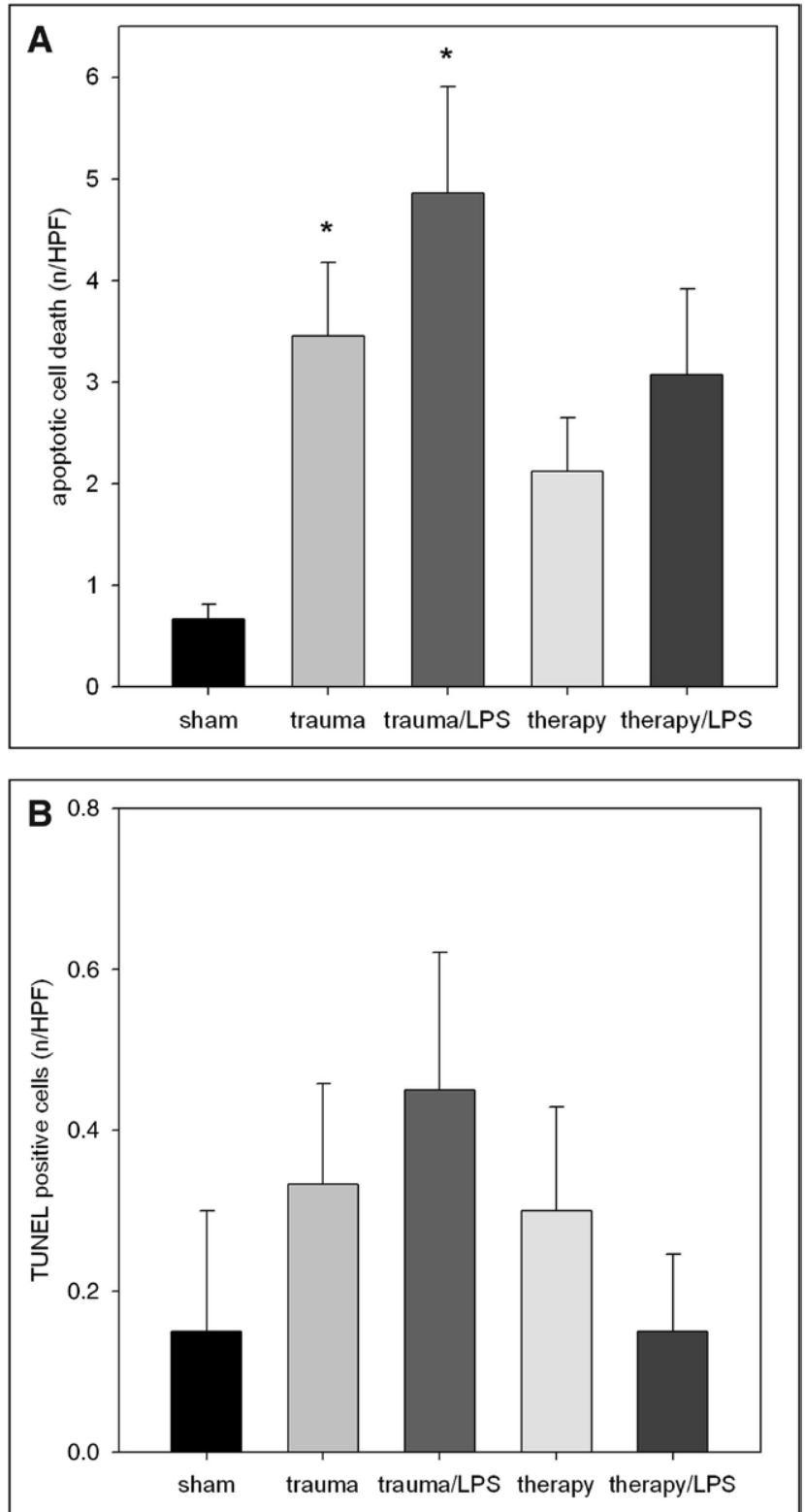

Figure 3. Quantitative analysis of cell apoptosis, as assessed by in vivo staining with bisbenzimide $(\mathbf{A})$ or by indirect in situ DNA nick-end labeling (terminal deoxynucleotidyl transferase dUTP nick-end labeling [TUNEL]) assay (B) of skeletal muscle tissue in animals at $24 \mathrm{hrs}$ after soft-tissue trauma and subsequent exposure to lipopolysaccharide (LPS). Animals were treated either with antithrombin (therapy; therapy/LPS) or vehicle solution (trauma; trauma/LPS). Sham-operated animals without trauma and endotoxemia (sham) served as controls. Values are given as mean \pm SEM. ${ }^{*} p<0.05$ vs. sham. HPF $=$ high-power fields.

mechanisms of antithrombin-mediated protection intraumatized patients with sepsis.

In summary, the protective effect of antithrombin on traumatized skeletal muscle tissue implies that antithrombin reveals potent anti-inflammatory properties to prevent skeletal muscle from secondary tissue damage in order to hasten healing and to improve performance following closed soft-tissue injury. Furthermore, we observed effective amelioration of tissue perfusion and thus adequate tissue oxygen supply. Despite its wellknown anticoagulatory properties, we did not observe adverse side effects, like bleeding complications in traumatized tissue. Our investigation shows that the anticoagulant pathway of antithrombin may represent one key mechanism in preventing traumatized muscle tissue from microvascular dysfunction in a double-hit model.

\section{ACKNOWLEDGMENTS}

We thank Berit Blendow, Doris Butzlaff, Dorothea Frenz, and Maren Nerowski (Institute of Experimental Surgery, University of Rostock) for excellent technical assistance and Helga Krentz (Institute for Biostatistics and Informatics in Medicine and Ageing Research, University of Rostock) for the statistical review of the manuscript.

\section{REFERENCES}

1. Angus DC, Linde-Zwirble WT, Lidicker J, et al: Epidemiology of severe sepsis in the United States: Analysis of incidence, outcome, and associated costs of care. Crit Care Med 2001; 29:1303-1310

2. Abraham E, Reinhart K, Svoboda P, et al: Assessment of the safety of recombinant tissue factor pathway inhibitor in patients with severe sepsis: A multicenter, randomized, placebo-controlled, single-blind, dose escalation study. Crit Care Med 2001; 29:2081-2089

3. Levi M, de Jonge E, van der Poll T: New treatment strategies for disseminated intravascular coagulation based on current understanding of the pathophysiology. Ann Med 2004; 36:41-49

4. Rao LV, Nordfang $\mathrm{O}$, Hoang AD, et al: Mechanism of antithrombin III inhibition of factor Vlla/tissue factor activity on cell surfaces. Comparison with tissue factor pathway inhibitor/factor Xa-induced inhibition of factor Vlla/tissue factor activity. Blood 1995; 85:121-129

5. Roemisch J, Gray E, Hoffmann JN, et al: Antithrombin: A new look at the actions of a serine protease inhibitor. Blood Coagul Fibrinolysis 2002; 13:657-670

6. Hoffmann JN, Fertmann JM, Jauch KW: Microcirculatory disorders in sepsis and transplantation: Therapy with natural coagulatory inhibitors antithrombin and activated protein C. Curr Opin Crit Care 2006; 12: 426-430

7. Oelschläger C, Römisch J, Staubitz A, et al: Antithrombin III inhibits nuclear factor kappaB activation in human monocytes and vascular endothelial cells. Blood 2002; 99:4015-4020

8. Hoffmann JN, Vollmar B, Römisch J, et al: Antithrombin effects on endotoxin-induced microcirculatory disorders are mediated mainly by its interaction with microvascular endothelium. Crit Care Med 2002; 30:218-225

9. Schaser $\mathrm{KD}$, Vollmar $\mathrm{B}$, Menger $\mathrm{MD}$, et al: In vivo analysis of microcirculation following closed soft-tissue injury. J Orthop Res 1999; 17: 678-685

10. Dixon CE, Clifton GL, Lighthall JW, et al: A controlled cortical impact model of traumatic brain injury in the rat. $J$ Neurosci Methods 1991; 39:253-262

11. Lighthall JW, Dixon CE, Anderson TE: Experimental models of brain injury. J Neurotrauma 1989; 6:83-97

12. Tyml $\mathrm{K}$, Budreau $\mathrm{CH}$ : A new preparation of rat extensor digitorum longus muscle for intravital investigation of the microcirculation. Int J Microcirc Clin Exp 1991; 10:335-343

13. Mittlmeier T, Vollmar B, Menger MD, et al: Small volume hypertonic hydroxyethyl starch reduces acute microvascular dysfunction after closed soft-tissue trauma. J Bone Joint Surg Br 2003; 85:126-132

14. Gierer P, Mittlmeier T, Bordel R, et al: Selective cyclooxygenase-2 inhibition reverses microcirculatory and inflammatory sequelae of closed softtissue trauma in an animal model. J Bone Joint Surg Am 2005; 87: 153-160

15. Kim D, Armenante PM, Durán WN: Transient analysis of macromolecular transport across microvascular wall and into interstitium. Am J Physiol 1993; 265(3 Pt 2):H993-H999 
16. Vollmar B, Burkhardt M, Minor T, et al: High-resolution microscopic determination of hepatic NADH fluorescence for in vivo monitoring of tissue oxygenation during hemorrhagic shock and resuscitation. Microvasc Res 1997; 54:164-173

17. Chance $B$, Cohen $P$, Jobsis $F$, et al: Intracellular oxidation-reduction states in vivo. Science 1962; 137:499-508

18. Glanemann M, Vollmar B, Nussler AK, et al: Ischemic preconditioning protects from hepatic ischemia/reperfusion-injury by preservation of microcirculation and mitochondrial redox-state. $J$ Hepatol 2003; 38:59-66

19. Mizutani A, Okajima K, Uchiba M, et al: Antithrombin reduces ischemia/ reperfusion-induced renal injury in rats by inhibiting leukocyte activation through promotion of prostacyclin production. Blood 2003; 101 : 3029-3036

20. Murakami K, McGuire R, Cox RA, et al: Recombinant antithrombin attenuates pulmonary inflammation following smoke inhalation and pneumonia in sheep. Crit Care Med 2003; 31:577-583

21. Sorg H, Hoffmann JN, Menger MD, et al: Antithrombin is as effective as heparin and hirudin to prevent formation of microvascular thrombosis in a murine model. Thromb Haemost 2006; 96:371-377

22. Sorg H, Hoffmann JN, Rumbaut RE, et al: Efficacy of antithrombin in the prevention of microvascular thrombosis during endotoxemia: An intravital microscopic study. Thromb Res 2007; 121:241-248

23. Kaneider NC, Reinisch CM, Dunzendorfer S, et al: Syndecan-4 mediates antithrombin-induced chemotaxis of human peripheral blood lymphocytes and monocytes. J Cell Sci 2002; 115(Pt 1):227-236

24. Eisele B, Lamy M, Thijs LG, et al: Antithrombin III in patients with severe sepsis. A randomized, placebo-controlled, double-blind multicenter trial plus a meta-analysis on all randomized, placebo-controlled, double-blind trials with antithrombin III in severe sepsis. Intensive Care Med 1998; 24:663-672

25. Warren BL, Eid A, Singer P, et al: Caring for the critically ill patient. Highdose antithrombin III in severe sepsis: A randomized controlled trial. JAMA 2001; 286:1869-1878

26. Dellinger RP, Levy MM, Carlet JM, et al: Surviving Sepsis Campaign: International guidelines for management of severe sepsis and septic shock: 2008. Crit Care Med 2008; 36:296-327

27. Kienast J, Juers M, Wiedermann CJ, et al: Treatment effects of high-dose antithrombin without concomitant heparin in patients with severe sepsis with or without disseminated intravascular coagulation. J Thromb Haemost 2006; 4:90-97

28. Gierer P, Hoffmann JN, Mahr F, et al: Sublethal trauma model with systemic endotoxemia for the study of microcirculatory disorders after the second hit. J Surg Res 2008; 147:68-74

29. Ince $\mathrm{C}$, Coremans JM, Bruining HA: In vivo NADH fluorescence. Adv Exp Med Biol 1992; 317:277-296

30. De Backer D, Donadello K, Taccone FS, et al: Microcirculatory alterations: Potential mechanisms and implications for therapy. Ann Intensive Care $2011 ; 1: 27$

31. Marechal X, Favory R, Joulin O, et al: Endothelial glycocalyx damage during endotoxemia coincides with microcirculatory dysfunction and vascular oxidative stress. Shock 2008; 29:572-576

32. Tsen A, Kirschenbaum LA, LaRow $C$, et al: The effect of anticoagulants and the role of thrombin on neutrophil-endothelial cell interactions in septic shock. Shock 2009; 31:120-124 